\title{
3 tons pure electric vehicles power system design based on
}

\section{Cruise}

\author{
LIU Xinyu, TIAN Houjie
}

Tianjin Transportation Vocational College, Tianjin300110, China

\begin{abstract}
The pure electric minivan is different from electric car. Combined with a given vehicle, vehicle simulation model established in Cruise software, complete simulation by setting tasks for the selected models designed drivetrain. Simulation results show that: The design of the transmission ratio can best meet the performance requirements of the matching target power analysis and simulation of electric minivan provides a new way, with practical guidance.
\end{abstract}

Key words: pure electric minivan; simulation model; Cruise; match

\section{INTRODUCTION}

With the increasingly prominent environmental protection and energy problems, pure electric vehicles become the development direction of many large car enterprises and research institutes because of their advantages such as zero emission and low noise. The pure electric mini truck usually travels in the city or the suburbs. By optimizing the power system, the system can reduce the system loss, prolong the mileage and improve the efficiency of the whole vehicle. Before the battery problem, how to choose the reasonable parts and related parameters, the optimal matching conditions, in the same battery, better meet the requirements of vehicle power and increases the range, researchers always pursue the goal of this paper is [1], the main purpose of the research.

In this paper, a model of pure electric vehicle of Tang Jun company is taken as an example to design the transmission system parameters of the whole vehicle. Because the motor itself has the function of starting Table 1 structural parameters of whole vehicle

\begin{tabular}{|c|c|c|c|c|}
\hline $\begin{array}{c}\text { Mass } \\
\mathrm{kg}\end{array}$ & $\begin{array}{c}\text { Full } \\
\text { load } \\
\text { mass } \\
/ \mathrm{kg}\end{array}$ & $\begin{array}{c}\text { Windwa } \\
\text { rd area } \\
/ \mathrm{m}^{2}\end{array}$ & $\begin{array}{c}\text { drag } \\
\text { coefficient }\end{array}$ & $\begin{array}{c}\text { Wheelbas } \\
\mathrm{e} / \mathrm{mm}\end{array}$ \\
\hline 1500 & 3000 & 1.65 & 0.35 & 2000 \\
\hline $\begin{array}{c}\text { Wheel rolling } \\
\text { radius } / \mathrm{m}\end{array}$ & $\begin{array}{c}\text { Final } \\
\text { reductio } \\
\mathrm{n} \text { ratio }\end{array}$ & $\begin{array}{c}\text { Coefficien } \\
\text { tof rolling } \\
\text { resistance }\end{array}$ & $\begin{array}{c}\text { transmissi } \\
\text { on } \\
\text { efficiency }\end{array}$ \\
\hline \multicolumn{2}{|c|}{0.265} & 4.4 & 0.0165 & 0.92 \\
\hline
\end{tabular}

Table 2 dynamic performance requirements

\begin{tabular}{|c|c|c|}
\hline $\begin{array}{c}\text { No-load } \\
\text { maximum } \\
\text { speed } \mathrm{Km} / \mathrm{h}\end{array}$ & $\begin{array}{c}\text { Full load } \\
\text { maximum } \\
\text { speed } \mathrm{km} / \mathrm{h}\end{array}$ & $\begin{array}{c}\text { Maximum } \\
\text { climb\% }\end{array}$ \\
\hline 80 & 65 & 20 \\
\hline $\begin{array}{c}\text { Acceleration } \\
\text { time s } \\
(0 \sim 40 \mathrm{~km} / \mathrm{h})\end{array}$ & $\begin{array}{c}\text { Continued } \\
\text { mileage } \mathrm{km}\end{array}$ & \\
\hline 10 & 85 & \\
\hline
\end{tabular}
with load and has the function of speed regulation, the transmission structure adopted should be simpler. The structural parameters and target dynamic performance of the vehicle are as follows: 


\section{MATCHING OF PURE ELECTRIC VEHICLE TRANSMISSION SYSTEM}

\section{1 determination of motor parameters}

Pure electric micro trucks often work in the suburbs, and run in the starting, acceleration, deceleration, climbing, braking and other conditions, so the drive motor to meet the needs of various operating conditions.

\section{Power selection of 1.1.1 motor}

The power size of the motor is directly related to the power performance of the electric vehicle. The motor power is, the better the acceleration and climbing performance of electric vehicles, but the size and quality of the motor will also increased, at the same time the motor can not always keep working in high efficient area, reduced the rate and the vehicle mileage by using the energy of pure electric vehicles. Therefore, the selection of motor power plays a vital role in the dynamic performance of the whole vehicle [2].

1) to meet the maximum speed requirements, the power required by the motor is:

$$
P_{1} \geq \frac{v_{\max }}{3600 \eta_{T}}\left(m g f+\frac{C_{D} A v_{\max }^{2}}{21.15}\right)
$$

The corresponding parameters are taken into account: $\mathrm{P}_{1}=7.32 \mathrm{kw}$

2) to meet the requirements of climbing performance, the power required by the motor is:

$$
P_{2} \geq \frac{v}{3600 \eta_{T}}\left(m g f \cos (\arctan \alpha)+m g \sin (\arctan \alpha)+\frac{C_{D} A v^{2}}{21.15}\right)
$$

The corresponding parameters are taken into account: $\mathrm{P}_{2}=8.65 \mathrm{kw}$

3) the total power required by the vehicle acceleration performance index is calculated. Assuming that the output characteristic of the motor is equal to the power, the [3] can be deduced from the dynamic equilibrium equation:

$$
v=v_{m}\left(t / t_{m}\right)^{0.5}
$$

$\mathrm{Vm}$ - the final speed of the acceleration process; $\mathrm{TM}$ - the time required to accelerate the speed from 0 to $\mathrm{Vm}$
According to the hypothesis, the total power of the power source in the whole acceleration process is constant, and the average power and the output speed of the power output in the whole acceleration process are the same when the power source output power is the maximum. The total power required for the acceleration process is derived as follows:

$P_{3} \geq \frac{1}{3600 t_{m} \eta_{T}}\left(m g f \frac{v_{m} t_{m}}{1.5}+\frac{C_{D} A v_{m}{ }^{3}}{21.15^{*} 2.5} t_{m}+\delta m \frac{v_{m}^{2}}{2}\right)$

The corresponding parameters are taken into account: $\mathrm{P}_{3}=18.45 \mathrm{kw}$

In order to ensure the design of the vehicle can travel at the maximum speed is constant, and meet the climbing performance and accelerating performance requirements, the design of motor rated power should be greater than $\mathrm{P} 1$, in the range of overload permitted (overload 3-5 times), to meet the power requirements and accelerate climbing.

Determination of torque of 1.1.2 motor

The main reduction ratio of pure electric vehicles is Io. When the speed reaches the highest speed, it is usually on the direct gear $\mathrm{n}>\mathrm{i}_{\mathrm{g}} \mathrm{i}_{\text {ov }} / 0.377 \mathrm{r}$ to meet the Maximum speed of motor. In the motor overload allowed range, select the motor rated speed. Then, the rated torque and maximum torque of the motor are determined by the rated power and the rated speed.

The motor type is selected according to the basic motor parameters determined above.

\subsection{Design of transmission ratio of transmission}

The principle of transmission ratio and gear position determination: two main power and resistance balance points need to be considered in motor drive. One is the torque balance of the conventional speed, and the two is the torque balance point at the highest speed [4]. According to the operating characteristic curve of the motor, the power balance diagram of the motor under the maximum speed and the basic frequency is plotted. 


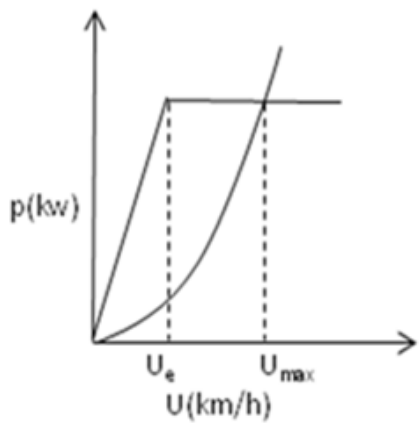

Fig. 1 power balance diagram of pure electric vehicle

$$
\text { of } \mathrm{n}_{\max } / n_{e}>2.5
$$

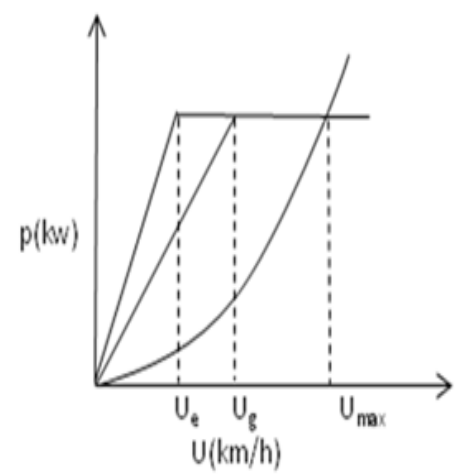

Fig. 2 power balance diagram of pure electric vehicle

$$
\text { of } \mathrm{n}_{\max } / n_{e} \leq 2.5
$$

1) as shown in Figure 1: when the maximum speed of the motor and the basic speed ratio of $>2.5$, the motor speed range from the basic frequency is large enough to select a stall to meet the requirements. But this kind of situation requires higher motor, it is difficult to guarantee that the inverter always works in high efficiency area.

2) as shown in Figure 2: maximum motor speed and pitch speed ratio is less than 2.5, the motor from the baseband to speed range is not wide enough, should consider to add a file.

At the same time, pure electric mini truck driving at top speed, with minimum transmission ratio of driving gear; the maximum gradient, the maximum transmission ratio of driving gear, and the gear ratio of known io $=4.6$, the largest, small transmission range from the following two type available:

$$
\begin{aligned}
& i g_{\max } \geq \frac{m g(f \cos (\arctan \alpha)+\sin (\arctan \alpha)) r}{T_{\max } \eta_{T_{T}}} \\
& i g_{\min } \leq \frac{0.377 r n_{\max }}{v_{\max } i_{o}}
\end{aligned}
$$

Within the allowable range of the transmission ratio, the smaller the transmission ratio, the less the gear set, and the simpler the structure. However, smaller transmission ratios may result in a decrease in climbing performance. Therefore, the number of gears is determined according to the maximum speed of the motor and the speed ratio of the rated motor. Combining the range of transmission ratio obtained by type 5 and 6 , the preset transmission ratio, the simulation model is established, and the simulation results are optimized continuously.

\section{3 power battery type selection}

The operation of pure electric vehicles rely entirely on battery energy, battery can provide timely backup power in the vehicle load conditions, regenerative braking can absorb energy, thus requiring battery with high energy and high power and long service life cycle. In addition, the utility model also has good use safety performance and self discharge performance. Currently available for electric vehicles, power batteries are mainly lead-acid batteries, lithium-ion batteries, Ni-MH batteries, super capacitors and so on. Because of the advantages of Ni-MH cell such as high energy density, high power density, fast charge and low cost, we use Ni-MH cell in this design.

In order to meet the design goals of the dynamic performance and driving range requirements, in accordance with the calculation of the vehicle speed is set to the level of wind resistance: good road, calculate the driving force required in the work condition, and according to the relationship between power, force and distance from the stroke energy required for [5]. Ni-MH battery is selected as the object, full of power, calculated according to SOC $100 \%$, discharge $90 \%$, the rated voltage of the battery is determined by the selected motor, and the rated capacity of the battery is calculated according to the energy balance.

The battery capacity mainly guarantees the power demand of the electric vehicle and the need of the continuous mileage, and the battery number can be selected according to the maximum power and the driving range. 
The number of cells determined by the maximum power is the number of cells:

$$
N=\frac{P_{e \max }}{P_{b \operatorname{maax}} \eta_{e} \eta_{e c}} \text { (7) }
$$

Pemax is motor, maximum power is $\mathrm{kW}$;

$\mathrm{P}_{\mathrm{bmax}}$ is the maximum output power of single cell $\mathrm{kW}$; $\eta_{\mathrm{e}}$ for motor efficiency;

$\eta_{\mathrm{ec}}$ is the working efficiency of the motor controller.

Number of battery cells determined by continued mileage

The number of battery cells determined by the continued mileage shall be:

$$
N=\frac{1000 L W}{C_{i} U_{i}}
$$

Type (8): $\mathrm{L}$ is the driving range of electric vehicle $\mathrm{km}$; $\mathrm{Ui}$ is the single cell voltage $\mathrm{V}$;

$\mathrm{Ci}$ is a single cell rated capacity $\mathrm{A} * \mathrm{~h}$;

W consumes energy per unit mileage of an electric vehicle $\mathrm{kJ}$.

The larger value of $\mathrm{N}$ in formula (7) and formula (8) is the required number of battery monomers .

\section{EXAMPLE BASED DESIGN PROCESS}

In order to improve the development of pure electric vehicles of a certain type of Tang Jun company as an example, according to the design requirements of the power, in accordance with the design process mentioned above, the optimized matching transmission system of vehicle, and simulation model is established by using cruise software. Through further analysis of the simulation results, optimize the transmission system, so as to achieve the power requirements while improving transmission efficiency. For the example of a Tang Jun model of a pure electric truck, the basic parameters of the motor and battery are selected as shown in table 3:

Table 3 basic parameters of selected motors and

\begin{tabular}{|c|c|c|}
\hline \multicolumn{3}{|c}{ batteries } \\
\hline \multirow{3}{*}{ Motor type } & Rated / & Rated / \\
& maximum & maximum \\
& power & speed \\
& $\mathrm{Kw}$ & $\mathrm{r} / \mathrm{min}$ \\
\hline
\end{tabular}

\begin{tabular}{|c|c|c|c|}
\hline \multicolumn{2}{|c|}{$\begin{array}{c}\text { Permanent magnet } \\
\text { brushless DC motor }\end{array}$} & $7.5 / 18.5$ & $2000 / 3500$ \\
\hline $\begin{array}{c}\text { Rated / } \\
\text { maximum } \\
\text { torque } \\
\text { N.m }\end{array}$ & $\begin{array}{c}\text { Battery } \\
\text { type }\end{array}$ & $\begin{array}{c}\text { Rated } \\
\text { voltage of } \\
\text { battery } \\
\text { V }\end{array}$ & $\begin{array}{c}\text { Rated } \\
\text { capacity of } \\
\text { battery } \\
\text { Ah }\end{array}$ \\
\hline $36 / 60$ & Ni-MH & 120 & 200 \\
\hline
\end{tabular}

\section{SIMULATION MODELING RESULT ANALYSIS}

\section{1 modeling and calibration of pure electric vehicles based on AVL CRUISE}

AVL Cruise software is used for the study of vehicle dynamics, fuel economy, emission performance and braking performance of advanced simulation analysis software. The software can be used in powertrain matching, vehicle performance prediction, and modeling, simulation and performance simulation of hybrid vehicles and electric vehicles.

Based on the Cruise platform, a miniature pure electric truck model is built up as shown in figure 3. The model mainly includes wheel model, main reducer model, transmission model, motor model, battery model and driver model.

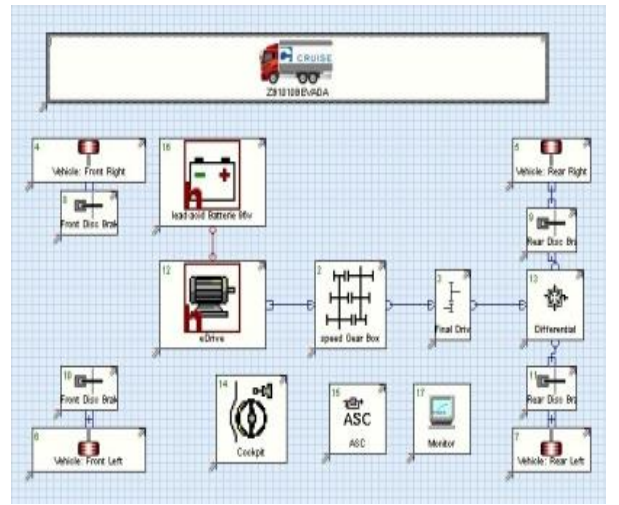

Figure 3 vehicle model

After the vehicle model is completed, the parameters of each module are set up, and the physical connection between the modules is established and the signal is connected. By adding relevant calculation tasks, the pure electric vehicle is operated in a given set of working conditions. According to the traffic conditions of the city, added Climbing Performance, Constant Drive, Full load Acceleration, Cycle run four 
computing tasks, respectively to verify the design of vehicle climbing performance, maximum speed, acceleration, mileage.

Due to the objective conditions, the parameters of the whole vehicle and parts needed for the accurate model of Cruise can not be obtained. In order to make the model precise, the model is calibrated by using the existing data. In this design, we use the parameters of the original car and the experimental data for calibration. The parameters of the original car into the model, the simulation results are compared with experimental results, to adjust the parameters in the model can not be accurately obtained according to the error, until the error of simulation results and experimental results in the set range, calibration [7].

When the model is built and calibrated, the model is checked to see if there are any problems such as module definition, information connection, data input error and so on. After checking, the model can be run for task calculation, and the result of simulation data will be automatically generated in file form at Result Manger.

\section{2 simulation results analysis}

By adding a model to the cruise software, a calculation task is added to the transmission ratio. The simulation results show that in the design phase, through the use of Cruise for vehicle optimization matching, not only improve the performance of the whole vehicle, but also shorten the design cycle, reduce design costs and shorten the feedback chain. Among them, ig1 $=2.55$, ig2 $=1.8$, simulation results are as follows:

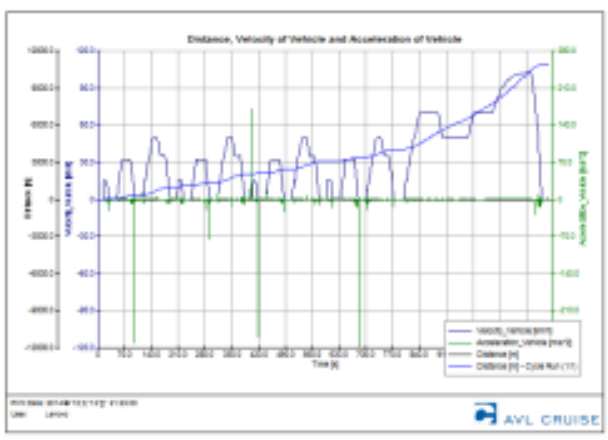

Figure 4 no gear mode, continuous mileage under one NEDC condition

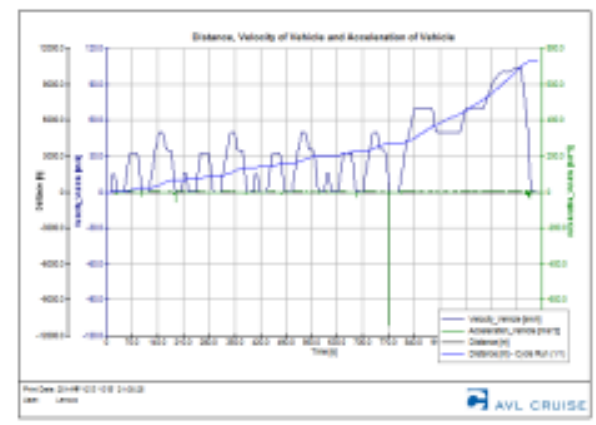

Figure 5 two stall mode, once NEDC conditions, continued mileage

As can be seen from Figure 4 and figure 5, in the case of a NEDC, the speed of the pure electric vehicle and the continuous mileage of the two models are not very different. Compared with the two gear mode, the model is more ideal, but it has little advantage. This is because the required speed, acceleration performance, no gear and two gears are not very different from each other under this working condition. Therefore, as to the NEDC working condition, which of these two gears can be chosen, all of them can meet the requirements.

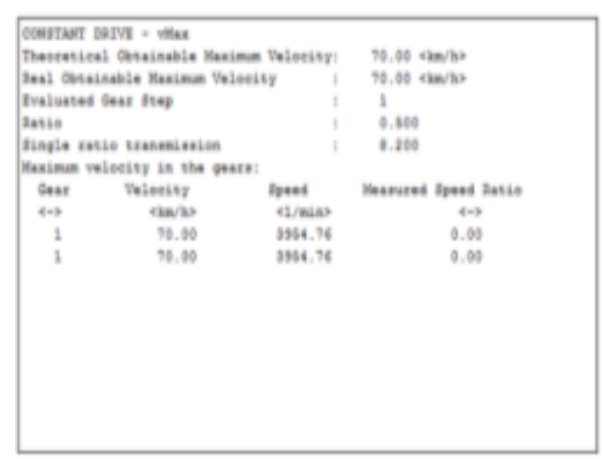

Figure 6 maximum speed without stall mode

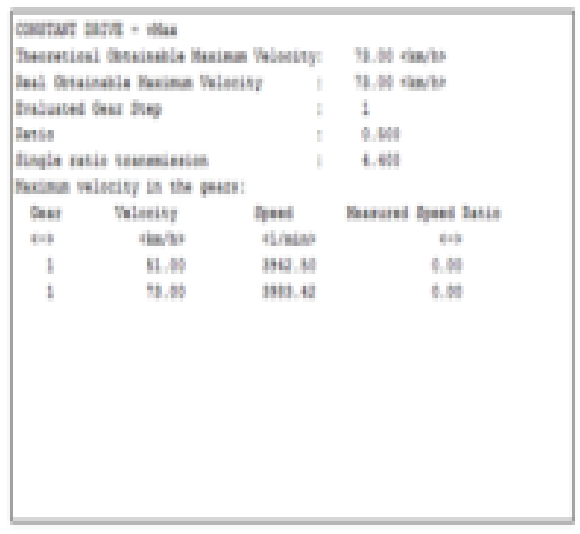

Figure 7 two gear mode top speed

From Figure 6 and Figure 7 shows, two stalls under the mode of the maximum speed of pure electric 
vehicles is the highest, reaching $72 \mathrm{~km} / \mathrm{h}$, there is relatively low but the two little difference between the maximum speed gear mode, and pure electric vehicles $3 \mathrm{~T}$ total power quality requirements are relatively high, without excessive speed. This is because the two stalls will change the transmission mode than the transmission system for high speed, sacrificing some performance, so pure electric vehicles two gear mode the highest speed is relatively high, but the pure electric vehicles running in urban areas of major truck speed is not high. Thus, the two models are available for maximum speed.

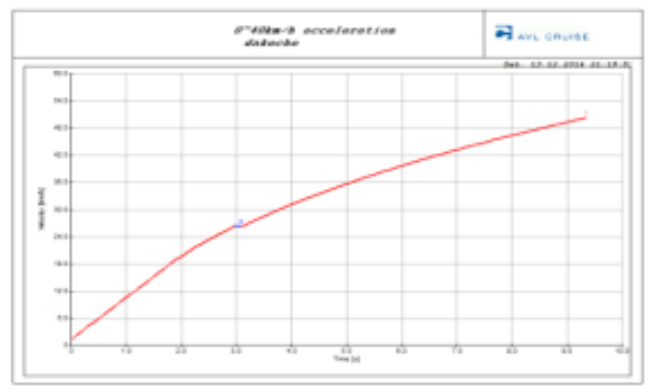

Figure 8 no stall mode $0 \sim 40 \mathrm{~km} / \mathrm{h}$ acceleration time

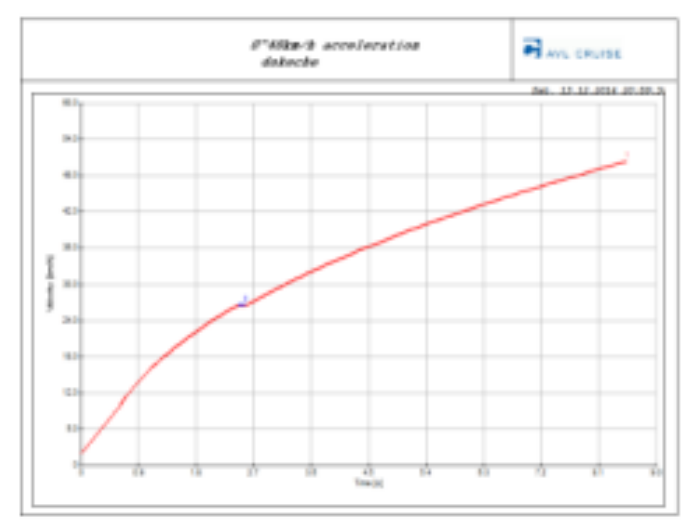

Figure 9 no stall mode $0 \sim 40 \mathrm{~km} / \mathrm{h}$ acceleration time From figure 8 and Figure 9 shows, without shift mode, pure electric vehicles speed from 0 up to $40 \mathrm{~km} / \mathrm{h}$ to about $5.5 \mathrm{~s}$; while the two gear mode, electric truck speed from 0 up to $40 \mathrm{~km} / \mathrm{h}$ only $5 \mathrm{~S}$, shorter time. This is because the two gear mode drive system can sacrifice more energy for acceleration, so the acceleration capability is better. Therefore, in terms of acceleration time, the $3 \mathrm{~T}$ pure electric vehicle chooses the two gear mode best.

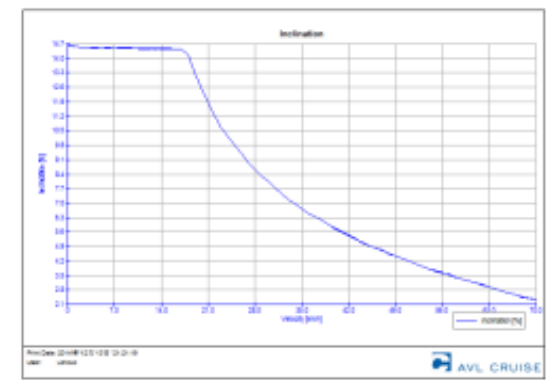

Fig. 10 maximum climbing grade without stall mode

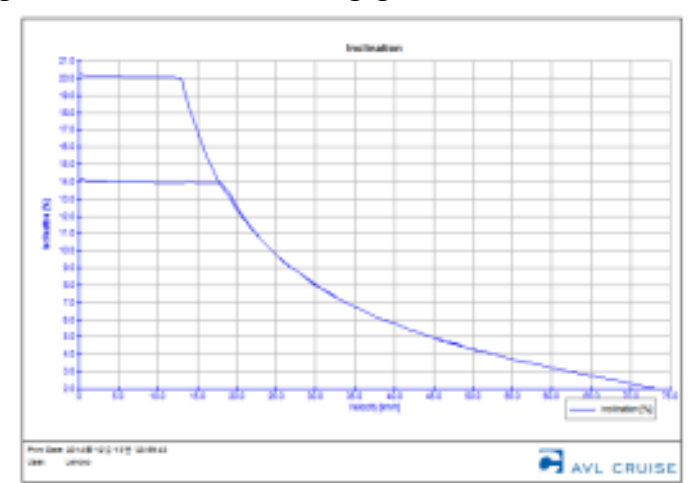

Fig. 11 maximum climbing grade of two stall mode From Figure 10 and Figure 11 shows that the pure electric vehicle maximum climbablegradient maximum reached 20 under the two gear mode, this is because the two gear mode can choose 1 gear low gear, the speed is very low at this time, the same power for climbing more energy, so the maximum climbablegradient greater. Therefore, the two gear mode is the best for the maximum climbing grade.

\section{CONCLUSION:}

Power system is the core component of a car, which is particularly important for a pure electric vehicle. This design uses the manual gearbox with the main reducer, transmission power, the mini truck from the mini car, dynamic performance of the manual file can quickly improve the automobile, expand the scope of work in high efficiency area of the motor, save climbing, acceleration time, extended mileage.

In this design, an example of a pure electric truck of Tang Jun company is analyzed, the motor and battery are selected according to the dynamic performance index, and the range of the drive ratio is set. Combined with AVL Cruise software, the whole vehicle model is set up, and the calculation task is established by setting up the matrix operation of the 
transmission ratio. The simulation results show that this design and simulation have strong feasibility and rationality for matching the power system of pure electric vehicle, and greatly reduce the complexity of the traditional design and verify the optimization process.

\section{REFERENCE:}

[1] Yu Zhisheng car theory [M]. 5th edition, Beijing Machinery Industry Press,

[2] Zhai Li, Sun Fengchun. Electric car matching calculation and simulation of electromechanical drive system. [J]. Beijing University of Technology, 2007,3(10):869-873

[3] Dai Tianlu. pure electric car drive system design and matching parameters [C]. Symposium Chinese Society of Automotive Engineers, 2011, 2 (1): 1283-1286

[4] Ceng Hu, Huang Juhua. Pure electric vehicle motor and transmission matching $[\mathrm{J}]$. Equipment Manufacturing Technology Journal, 2010,12 (2): 40-42

[5] Zhu Zhengli, Yin Chengliang, Zhang Jianwu. Pure electric vehicle powertrain optimization parameters based on genetic algorithm $[\mathrm{J}]$ Shanghai Jiaotong University, 2004, 38 (11): 1907-1972.

[6] Chang Lv. Pure electric mini-car powertrain design and dynamic simulation parameters $[\mathrm{J}]$. Mechanical design and manufacturing, 2010(6):43-45

[7] WANG Guo-rong, ZHAO Fu-quan. Study on Matching Optimization of Automotive Power Train Based on Cruise [J]. Automotive Engineer, 2013(4):29-31.

Corresponding author: Liu Xinyu, (1972-) male, Tianjin, master degree in automotive, electrical and electronic technology.1617596880@qq.com. 